\title{
Futuristic Medicine and its Applications in the Field of Medical Science
}

\author{
Niranjan Bhattacharya and Priyodarshi Sengupta* \\ Department of Regenerative Medicine and Translational Science, Calcutta School of Tropical Medicine, India \\ *Corresponding author: Priyodarshi Sengupta, Department of Regenerative Medicine and Translational Science, Calcutta School of Tropical Medicine
}

Submission: 非 January 25, 2018; Published: 潕 August 30, 2018

\begin{abstract}
The science of medicine has always influenced and played a major role in the evolution and development of a modern and sophisticated healthcare system. With basic and clinical sciences merging together, the advent of newer multi disciplinary branches in medicine has been always possible. Societal expectations and changes also played a major role in developing new therapies and techniques. Some of the most interesting field of medicines which have arisen in the past few decades are described below briefly in this small review of futuristic medicine and its clinical applications.
\end{abstract}

\section{Introduction}

During the early twentieth century, the idea of regenerating a new body part/organ to compensate lost and dead tissues would have seemed to be a story taken out from the pages of a science fiction book. There used to be huge sufferings and mortality from diseases like tuberculosis, polio, pneumonia, and malaria just to name a few. Cancer would have been a death penalty. AIDS was an unknown disease until 1983 [1]. Since the last three decades, medical science has made rapid strides and developed sophisticated tools for early diagnosis and detection. Presently, diseases like AIDS, malaria, hepatitis, pneumonia, tuberculosis, leprosy and even certain form of cancers are no longer considered to be fatal and deadly. Polio is now a closed chapter in many developing countries. The age we are currently living in, has become more materialistic and so are the demands and needs for a better healthcare system. This has encouraged many scientific communities globally to undertake and embark on new and futuristic journeys to achieve greater heights in the field of medical science. Massive funding from public and private institutions, emergence of science and scientist as a rewarding career, ever-increasing public awareness, inception of the concept of personalized medicine, competitiveness, quest for knowing the unknown and the willingness coupled with acceptance of the public to invest and pay more for a better health and treatment has helped in the advent of many avenues of modern medicine like Stem cell and Regenerative Medicine, Genomic and Molecular Medicine, Organ and Tissue Engineering and Nanomedicine. Many academics often collectively refer these branches of medicines as "Futuristic Medicine" which encompasses a diverse range of multi-disciplinary fields starting from basic biology to biomedical science, and from physical science to medical science.

\section{Classification of Futuristic Medicine}

Futuristic Medicine can be broadly classified into three groups:

A. Regenerative Medicine \& Cell Therapy

B. Nanomedicine

C. Genomic and Molecular Medicine

Regenerative Medicine can be further classified into two essential sub-branches as their applications form the very essence and backbone of this new branch of medicine. These are

a. Stem Cell and Progenitor Cell Therapy

b. Organ and Tissue Engineering (using biomaterials, cadaveric organs, tissues \& 3D Bio-printing)

\section{Regenerative medicine}

Regenerative Medicine (RM) is a branch of medical science which studies the rejuvenation, replacement and regeneration of human cells, tissue and organs, to counter mainly end stage and irreversible diseases [2]. Regenerative Medicine is multidisciplinary in its approach. It includes biomedical approaches to clinical therapies that involve the application of stem cells/progenitors' cells, cytokines, and growth factors [3].

It may also be done by inducing regeneration by biologically active molecules or by transplantation of in vitro grown organs and tissues through tissue engineering. Regenerative Medicine is an exciting new field that holds much promise for generating innovative therapies for a wide variety of diseases and disorders. 
Regenerative Medicine focuses on harnessing the body's own repair mechanisms to replace or heal damaged tissues and organs. This field can touch every ailment, ranging from cancer to heart disease to nervous disorders. This multidisciplinary field incorporates stem cell biology, tissue engineering, biomaterials engineering, and transplantation science. In addition, it also includes various enabling technologies and clinical application areas, with the goal of improving patient lives.

\section{Stem cells and cell therapy in regenerative medicine}

Ernest A McCulloch and James E Till in early 1960's showed that when bone marrow was injected into irradiated mice, the spleen developed nodules. This development of nodules further led to the conclusion that each of the nodules originated from a single marrow cell. They together further showed that these cells can self-renew and differentiate when required, the two hallmark properties of stem cells [4]. This gave rise to the concept of the presence of stem cells in the body. Since then cell therapy using stem cells have become an exciting branch of Regenerative Medicine. Unique examples of cell therapy are cord blood transfusion and transplantation, cellular transplantation, applications of healthy aborted and ethically collected fetal tissues, and pregnancy-specific biological substances all of which has been well documented and reported [5-9]. One of the most important areas of stem cell transplantation in Regenerative Medicine is its isolation from different sources, in vitro growth and development, and then applying them back in patients. Most of the classifications of stem cells are based on their availability from different sources and degree of potency. Some of the most common sources and types of stem cells that are currently under investigation are embryonic stem cells, mesenchymal stem cells, induced pluripotent stem cells, stem cells from cord blood, placenta, Wharton's Jelly, amniotic fluid and membrane, adipose tissue, skin, and brain $[7,8,10]$. Currently researchers are involved in identifying and characterizing stem cells from more and different sources. The last 50 years has seen some exciting advances in stem cell application with potential promise of treating diseases which are not possible with current medical knowledge and techniques. However most of these findings have been limited to a small cohort of patients and currently efforts are being undertaken to make these treatments more achievable in routine practice [11].

\section{D bioprinting, biomaterials, tissue \& organ engineering in regenerative medicine}

Three-dimensional bioprinting is a very new and emerging field of organ and tissue engineering that utilizes Bio-inks to deposit materials layer by layer to create artificial tissue-like structures. This branch of futuristic medicine covers broad areas of biomaterials and organ engineering [12]. 3D bioprinting is a multidisciplinary branch of futuristic medicine which utilizes cells for regeneration of the tissues or organs thereby making it suitable for transplantation. 3D bioprinting is currently under trial and is being viewed as a replacement and answer to global shortage of organ transplantation. 3D bioprinting has the capability to generate and mimic the anatomical structures of several tissues and is recently viewed as a unique tool for drug discovery and research [13]. Another exciting field of organ and tissue engineering is decellularization and recellularization technique of a whole organ production. It is a new technique that is rapidly gaining importance in regenerative medicine [14]. Decellularized cadaveric human donor organs collected ethically can be chemically and physically processed and modified into biological scaffolds. Many labs are currently trying to design and develop such type of whole organ biological scaffolds through recellularization techniques by reseeding these scaffolds with stem cells, progenitor cells and organ-specific cells for regeneration and transplantation [15-17].

\section{Nanomedicine}

The applications of nanotechnology in the last 10-20 years has ushered a new era in medical science where now diseases especially like cancer can be treated effectively with minimal side effects and toxicity [18]. Current clinical practices in cancer and in case of other debilitating diseases, aim at rejuvenating the healthier cells and destroying the diseased cells by means of pharmacotherapy and even surgery. In doing so many healthy cells are also destroyed in the process inadvertently resulting in short and long-term side effects on the patient's health [19]. With the help of Nanomedicine, we can now characterize the biological surfaces at the nanoscale level at predetermined locations and develop targeted and localized drug delivery approaches with enhanced biocompatibility and fewer side effects [20].

Iron oxide when coated with nanoparticles can be extremely resourceful in cancer imaging as these coated nanoparticles with their magnetic properties have shown to possess a strong affinity for binding to the specific tumors. This can allow in the processing of an accurate and high-resolution image of the tumor $[21,22]$ Like every futuristic medicine, the current limitations of nanomedicine as observed recently is their potential toxic effect on humans and environment including its abuse [23].

\section{Genomic and molecular medicine}

With the discovery of the RNA, DNA, proteins, genetic code, initiative of the Human Genome project, and technological advancements in the field of clinical genetics pertaining to the understanding of diseases, led to the advent of Genomic and Molecular Medicine, which is another interesting area of futuristic medicine [24]. Understanding how genes function, the role and synthesis of specific proteins in normal and diseased state and the genetic make-up of the individual, it is now possible to diagnose different diseases at the genetic and molecular level. Genomic and Molecular medicine has given rise to an entirely new method of diagnosing a disease. With the help of genomic medicine, we can now access and predict the patient's susceptibility to various diseases before the onset of any clinical symptoms [25]. Through genomic medicine we can also optimize the disease treatment by identifying the specific disease-causing genes and rectify them with yet another important discovery in gene editing technique known as Clustered regularly interspaced short palindromic repeatsCRISPR-associated protein 9 or CRISPR-Cas 9 [26]. 
This method of gene editing is still in its very early and infancy stage. Applications of genomic and molecular medicine can be also very handy and resourceful in epideomoglical and public health studies [27]. Pharmacogenomics, although it is still in its infancy stage is another potential area of genomic medicine which relates to the study of how genes affects the individual response to drugs [28,29]. It is becoming an essential tool and is often used in clinical trials and research for studying the effect of the trial drug on volunteers $[30,31]$. Currently the primary objective of the pharmacogenomic research is to allow the development of tailor-made drugs an essential step in the era of personalized medicine $[32,33]$.

\section{Conclusion}

It can be said without a doubt that miracles and discoveries in medical science and technologies have benefitted many patients globally and will continue to do so in the future also. With such emerging technologies in medical science, the rate of patient morbidity and mortality has also significantly reduced in case of many end-stage diseases. However, one thing that cannot even exclude futuristic medicine is the "human touch" without which medicine will always remain incomplete. Also, with great inventions come great risks. Most of the futuristic medicines that are discussed above comes with varying degrees of potential adversities and can be also abused substantially. It is up to the medical and research community how they are going to utilize the application and concept of futuristic medicine for the betterment of humanity keeping integrity and the cardinal principles of medical ethics "do no harm" intact.

\section{References}

1. Maartens G, Celum C, Lewin SR (2014) HIV infection: epidemiology, pathogenesis, treatment, and prevention. Lancet 384(9939): 258-271.

2. Center for Regenerative Medicine.

3. Nadia R, Stephen B (2016) Regenerative medicine: today's discoveries informing the future of medical practice. NPJ Regen Med 1: 16007.

4. Becker AJ, McCulloch EA, Till JE (1963) Cytological demonstration of the clonal nature of spleen colonies derived from transplanted mouse marrow cells. Nature 197: 452-454.

5. Gluckman E, Broxmeyer HE, Auerbacm AD, Friedman HS, Douglas GW, et al. (1989) Hematopoietic reconstitution in a patient with Fanconi's anaemia by means of umbilical cord from an HLA-identical sibling. N Engl J Med 321(17): 1174-1178.

6. Niranjan B, Phillip S (2009) Placental umbilical cord whole blood transfusion: A true blood substitute to combat Anaemia in the background of chronic disease-a study report (1999-2006). Frontiers of cord blood Science, Springer Verlag, London, pp. 227-263.

7. Niranjan B, Phillip S (2011) Regenerative medicine using pregnancy specific biological substances. Chapter No: 37, Use of Amniotic Membrane, Amniotic Fluid, and Placental Dressing in Advanced Burn Patients, Springer-Verlag London Limited, London, pp. 383-393.

8. Niranjan B, Phillip S (2009) Regenerative medicine using pregnancy-specific biological substances. Chapter No: 36 , Amniotic fluid and placental stem cells, Anthony Atala, Springer-Verlag London Limited, London, pp. 375-380.
9. Niranjan B, Phillip S (2013) Human fetal tissue transplantation. In: Niranjan B, Phillip S (Eds.), (1 $1^{\text {st }}$ edn), Chapter No: 1, Alternatives of Human Organ/Tissue Transplantation. Springer-Verlag, London, pp. 3-10.

10. Niranjan B, Stubblefield P (2015) Regenerative medicine using nonfatal sources of stem cells, ( $1^{\text {st }}$ edn). Somasundaram I, Marappagounder D (Eds.), ISBN:978-1-4471-6541-5, Identity of Human Endometrial Tissue: Potent Source of Stem Cells, Chapter No: 3, Springer-Verlag London, London, pp. 25-28.

11. http://www.thelancet.com/commissions/stem-cells

12. Wang X, Ao Q, Tian X (2016) 3D bioprinting technologies for hard tissue and organ engineering. In: Kai Chua C (Ed.), Materials, 9(10): 802.

13. Murphy SV, Atala A (2014) 3D Bioprinting of tissues and organs. Nature Biotechnology. Nat Biotechnol 32(8): 773-785.

14. Jung JP, Bhuiyan DB, Ogle BM (2016) Solid organ fabrication: comparison of decellularization to 3D bioprinting. Biomater Res 20(1): 27.

15. Chen FM, Liu X (2016) Advancing biomaterials of human origin for tissue engineering. Progress in Polymer Science 53: 86-168.

16. Maughan EF, Hynds RE, Proctor TJ, Janes SM, Elliott M, et al. (2017) Autologous cell seeding in tracheal tissue engineering. Curr Stem Cell Rep 3(4): 279-289.

17. Calle EA, Ghaedi M, Sundaram S, Sivarapatna A, Tseng MK, et al. (2014) Strategies for whole lung tissue engineering. IEEE Trans Biomed Eng 61(5): 1482-1496.

18. Patil M, Mehta DS, Guvva S (2008) Future impact of nanotechnology on medicine and dentistry. J Indian Soc Periodontol 12(2): 34-40.

19. Riehemann K, Schneider SW, Luger TA, Godin B, Ferrari M, et al. (2009) Nanomedicine-challenge and perspectives. Angew Chem Int Ed Engl 48(5): 872-897.

20. Fornaguera C, García CMJ (2017) Personalized nanomedicine: A revolution at the nanoscale. J Pers Med 7(4): E12.

21. https://www.etp-nanomedicine.eu/public/about-nanomedicine/nanomedicine-applications/nanomedicine-in-cancer

22. Shi J, Kantoff PW, Wooster R, Farokhzad OC (2017) Cancer nanomedicine: progress, challenges and opportunities. Nature reviews Cancer 17(1): 20-37.

23. Jahangirian H, Lemraski EG, Webster TJ, Rafiee MR, Abdollahi Y (2017) A review of drug delivery systems based on nanotechnology and green chemistry: green nanomedicine. Int J Nanomedicine 12: 2957-2978.

24. Hood L, Rowen L (2013) The human genome project: Big science transforms biology and medicine. Genome Medicine 5(9): 79.

25. Wall DP, Tonellato PJ (2012) The future of genomics in pathology. F1000 Med Rep 4: 14.

26. Lenardo M, Lo B, Lucas CL (2016) Genomics of immune diseases and new therapies. Annu Rev Immunol 34: 121-149.

27. Porteus MH (2015) Towards a new era in medicine: therapeutic genome editing. Genome Biol 16: 286

28. Zimmern RL, Khoury MJ (2012) The impact of genomics on public health practice: the case for change. Public health genomics. 15(3-4): 118-124.

29. Ventola CL (2011) Pharmacogenomics in clinical practice: reality and expectations. PT 36(7): 412-450.

30. Bloss CS, Dilip VJ, Nicholas JS (2011) Genomics for disease treatment and prevention. Psychiatr Clin North Am 34(1): 147-166.

31. Burt T, Dhillon S (2013) Pharmacogenomics in early-phase clinical development. Pharmacogenomics 14(9): 1085-1097. 
32. Surendiran A, Pradhan SC, Adithan C (2018) Role of pharmacogenomics in drug discovery and development. Indian J Pharmacol 40(4): 137-143.
33. Vogenberg FR, Isaacson BC, Pursel M (2010) Personalized medicine: Part 1: Evolution and development into theranostics. PT 35(10): 560576. (c) (i) Creative Commons Attribution 4.0

For possible submissions Click Here

Submit Article
GJEM Global Journal
of Endocrinolog
Metabolism

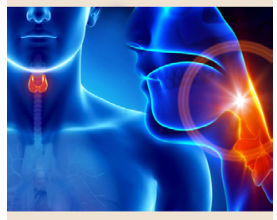

Global Journal of Endocrinological Metabolism

\section{Benefits of Publishing with us}

- High-level peer review and editorial services

- Freely accessible online immediately upon publication

- Authors retain the copyright to their work

- Licensing it under a Creative Commons license

- Visibility through different online platforms 